\title{
Phytoprotection
}

\section{Research Challenges and Needs for Safe Use of Microbial Organisms - The European Perspective}

\section{Bernard Blum}

Volume 79, numéro 4, 1998

OECD Workshop - Sustainable Pest Management, Safe Utilization of New Organisms in Biological Control. Montréal, Québec, Canada. September 27-30, 1998.

Atelier de l'OCDE - Gestion durable des ennemis des cultures, Utilisation sécuritaire de nouveaux organismes de lutte biologique. Montréal, Québec, Canada. 27-30 Septembre 1998.

URI : https://id.erudit.org/iderudit/706153ar

DOI : https://doi.org/10.7202/706153ar

Aller au sommaire du numéro

Éditeur(s)

Société de protection des plantes du Québec (SPPQ)l

ISSN

0031-9511 (imprimé)

1710-1603 (numérique)

Découvrir la revue

Citer cet article

Blum, B. (1998). Research Challenges and Needs for Safe Use of Microbial Organisms - The European Perspective. Phytoprotection, 79(4), 31-35.

https://doi.org/10.7202/706153ar d'utilisation que vous pouvez consulter en ligne. 


\title{
Research Challenges and Needs for Safe Use of Microbial Organisms The European Industry Perspective
}

\author{
Bernard Blum
}

International Biocontrol Manufacturers Association, 5, quai Voltaire, F-75007 Paris, France

\section{INTRODUCTION}

The safe utilization of new organisms for the biological control of pests must be regarded as a permanent aim, for all concerned parties.

The industry of which the basic function is to produce and bring to the market these products is particularly concerned with these safety aspects and is strongly committed to all aspects which will improve it.

However, we have to consider that "safety" may not have the same meaning for researchers, producers, marketers, users, regulators, consumers and the public. Furthermore the type of "new organism" has to be considered and should not be treated the same way. For exemple the biocontrol industry strongly opposes to be treated the same way as the chemical industry: safety aspects are very specific. Extrapolation from chemicals to biologicals is by nature wrong and will lead to illogical and impossible requirements.

We would like also to stress the point that "safety" is a dynamic concept which is due to evolve over the time according to scientific discoveries, the evolution of techniques and the opinion of users and consumers.

In this paper, the biocontrol manufactuers would like to point out some important European founded considerations on microbial organisms, and bring them to the attention of the researchers.

\section{The biocontrol market remains marginal and restricted to minor crops}

Looking to a worldwide plant protection market amounting to 21 Bio US \$/ annum, at users level, the Europe, with 5.3 US $\$$, is slightly larger than the share of North America (USA+Canada+ Mexico).

The main crops cultivated in Europe are Cereals, Oil seeds and Corn, followed by vines, fruit trees, Potatoes. Comparatively, vegetables and horticulture, especially in greenhouses and under plastic, cover a much smaller area.

Looking to the treated acreage, Cereals, Oil Seeds and Corn represent 85 Mio ha, Vines and Grapes 45 Mio, Fruit Trees 21 Mio, Potatoes 9 Mio. Vegetables and Horticulture, only 2.6 Mio ha.

This ranking is not exactly the same looking to the turnover of plant protection products sold: with 1'620 Mio \$, the Cereals market is still the most important, but followed by Vines $(945$ Mio), Corn (657 Mio), and Fruits (510 Mio).

With 217 Mio \$, the Vegetable market appears to be substantial, but has to be divided into a large number of crops and cultural practives. Each of these sub-markets must be considered as rather small, even sometimes difficult to quantify.

In comparison, the sales of biocontrol products, being used into IPM programes or in organic production, 
remains presently restricted to a few number of crops, basically vegetables and horticulture (19\% market share), Maize $(2,4 \%)$, Fruits $(1,9 \%)$, Vines $(1,6 \%)$. Almost nothing is sold in the other crops. The sales of biocontrol products amount to a total of about 80 Mio \$, of which $2 / 3$ are of microbials and microbial extracts.

\section{European agricultural policy: promoting IPM and organic farming, should boost the use of biocontrol agents}

Since the European Common Market has been established in Rome, the European Common Agricultural Policy (CAP) has been set up, showing the high attention given to agriculture. Indeed About $50 \%$ of the financial ressources of "Brussels" are indeed devoted to agriculture.

Although the first CAP has been drawn in order to drastically increase the European production and avoid expensive import, already the 1992 CAP reform, stressed on a more rational use of pesticides and the need to develop organic farming.

An important outcome of the Minister Meeting of Madrid, 1995, has been the "Agricultural Strategy Document", adopted in December 1995.

It is clearly mentionned that in order to improve its competitivity, the European agriculture should consider that the society becomes more concerned about the natural environment and that the consumers request safe and quality food. In order to fullfill these requirements, the production should be "sustainable and integrated".

These considerations are repeated again in several policy documents of the European Commission, including the EU report published in 1997 suggesting "The Possibilities for the Future EU Environmental Policy on Plant Protection Products". This document has to be considered as a major contribution to the EU policies related to the so called "AGENDA 2'000". It suggests:

1. to increase efforts toward organic and integrated agriculture
2. to pay subsidies in relation with actions leading to better safety and respect of the environment.

However, although substantial efforts are been made by the public authorities, including funding of many research programes and a large number of conferences held on this subject, the real growth of biocontrol, after a significant increase between 1980 and 1990, is slowing down since 1990 (table 2)

\section{Reasons of the lagging development of biological control agents}

Many factors have to be mentioned which are leading to the critical situation that the biocontrol industry is facing in Europe.

a. The industry itself has to be considered as partly responsible: the biocontrol industy is rather weak, lacking of ressources and capital. They cannot devote enough attention and means for the promotion of their products.

The chemical industry, in answer to the market needs, has been able to discover, develop and launch into the market, safer and more specific chemicals.

Finally we must also consider that the industry (some of the most important firms) is still missing of collegiability.We always again see firms which for one reason or the other prefer to follow alone their own track, instead of joining efforts with the other. This is the case for research, but also registration and extension activities.

b. The potential users are not educated or trained in order to understand properly how to enter into effective and safe biocontrol programes. They feel it complicated, unreliable, time consuming and expensive.

In the same line, the distribution have not understood the benefits of biologicals, have made no effort to adapt their marketing mix and their storage conditions to these products. Like the public, they express some kind of 
scepticism regarding their real benefits.

c. In reality the products brought to the market are still of mixed quality. Too many producers have not been able to market quality products, according to accepted standards.

Furthermore, the costs of production remain high due to the relative small scale of production.

d. The research organizations, are recently suffering from drastic budget cuttings. Funding from the European Commission. but not to the necessary extend, has been offered in compensation, in order to support CAP.

The research organizations are spending more money for speculative than applied research, extension and practical use of biologicals.

Furthermore, we must indicate that in many institutions, the researchers often have a detrimental lack of confidence toward the industry, suspected to only look for profit. They intend such a way, although they have little or no experience on practical production, development and use of biologicals. They like to be the only authorized spokemen for the biocontrol activity and the selected "experts"in the committees and working parties, created in order to promote biocontrol.

e. The public and regulatory agencies must be also mentioned, since they often intend, in order to avoid risks (ist that ever possible?), to build up regulations which scientifically, practically and economically make it more and more difficult to launch biological products into the market. As an exemple, the EU Directive 414/91 for microbial products will cost about $23 \%$ of the anticipated first cumulated 5 years of sales compared with only $1.8 \%$ for the chemical pesticides.

\section{Research challenges}

As we already reported it previously, the time is arrived for a decisive promotion of biocontrol agents: they are the necessary elements for integrated and organic farming practices.
The invertebrates beneficials are difficult and costly to produce in mass. The number of effective and reliable species for large field crops is still restricted. Their dynamic in an open environment a critical factor. Their formulation, packaging, storage, transportation and application techniques are not optimised. Finally they require a lot of attention and training from the farmers

The microbial preparations seem to be therefore better adapted to a fast and large expansion.

The technology for mass production is widely available, leading to substantial cost reduction potential. They are relatively easy to formulate, pack and apply. They do not require, in principle, too much specific attention and training from the users.

However, the industry is still facing significant challenges, from the research point of view.

1. The most important is the lack of in house financial ressources to be invested into research. Most of the companies are of small dimension, only a limited amount of risk capital is available in the market and the return on investment is not attractive enough, even for large plant protection firms which, deciding on protfolio strategies, prefer to invest in more profitable activities.

2. Another important problem is related to the agents to be marketed: the available strains still require to be optimised, in term of efficacy and stability in the environment:

Standards of quality, broadly accepted have to be established: as already mentionned this is a crucial condition in order to achieve the reliable necessary efficacy in the field..

Certainly this type of research would be better undertaken if the outcome would be better protected and the industrial property secured long enough in order to recover the investment costs.

3. For production, the most important is to search for cost reduction. This 
will be possible as soon as the market will require more important quantities, but efforts have still to be undertaken in order to develop more economic production process

Related to production, environmental issues, disposal etc... are still to be considered as critical.

Finally formulation and packaging must be handled with more specificity and competence.

4. The microbial control products are to be applied, sprayed over the crops or the cultivated land. However, very few has been made in order to develop specific application techniques. The products have to be formulated such a way that they will be used similarly as to chemical pesticides, although due to their living properties, their mode of action, their dynamic have nothing to do with inert chemical products.

5. A considerable effort has to be undertaken in order to ensure that the users, but also the consumers undertand the mode of action of microbial agents, their specific characteristics, their conditions of use and their dynamic in the environment..

In that respect, it is extremlely important that the users are motivated in order to contribute to a general monitoring scheme, and be able to report on the happening of strains used in the environment.

6. Finally, the regulatory agencies have to be more specific. Usuelly, the members of these agencies and the experts called for setting up the ad hoc committee, have a braod and long experience with the chemical pesticides. Their intend to extrapolate to microbials techniques and consideration which are relevant for inert active ingredients: the rules valid for air transportation cannot be extrapolated to railways, just because these are both transportation means.

The microbials agents, as well as the other biologicals, are of different nature than chemicals, they have genuine properties to be considered by edicting regulations.

\section{Research needs}

The industry would like to list 3 basic conditions which should be taken in consideration in regard to research activities:

1. Research activities on microbial control agents are justified by a market, therefore by users supplid by a viable biocontrol industry.

2. As much as possible, a large part of the $R \& D$ activities should be funded by the industry itself: The results will indeed only be exploited if their some kind of property attached to them.

The research activities may be undertaken within the firms themselves (this understates the availability of risks - funds) or through cooperative projects with public research institutions.

3. Regulatory agencies must systematically and better take in consideration the views of the industry. For example the new Expert Committee on Microbials Registration within the Directorate General XXIV (consumers) of the European Commision has created with 2 toxicologists, 3 microbiologists, but nobody from the industry.

Regarding the safe use of microbial control agents:

1. We consider that many aspects remain and will remain permamently to be studied, discovered, understood in order to allways improve the safety of used organisms.

In the meantime, risks have to be accepted, as long they do not appear to be damaging.

In order to have a better supervision of the problems, we suggest to to set up, for each category of microbial agent, a "Center of Excellence" (university or Research Institution). The Center of excellence, due to ist outstanding competence, will be coordinating research attached to the concerned agents. It will have the task of establishing "consensus documents", publically accessible. These documents will provide generic safe- 
ty data to producers, users, regulators and consumers.

2. Due to the relative low rate of microbials use, especially in large open field crops, like cereals, vines, fruit trees etc., we enjoy an exceptional situation: in order to do not repeat the mistake which occured after the uncontrolled introduction of chemical pesticides: and lead to environmental problems, it is possible to set up, already now at the starting point, monitoring scheme. The introduction, the use and the happening of the released organisms will be carefully stewarded. This will enable follow the dynamic of released products, study natural antagonisms, build up mathematical models and to early trace possible mutations, behavioural modifications etc. Necessary preventive and/or corrective adapted measures will be taken on time.

3. In order to increase use patterns and users satisfaction, especially in priority crops such as fruits, vines, cereals, oil seeds, it remains necessary to conduct standardised efficacy trials, to develop suitable application techniques, and more basically to adopt organic and integrated pest management strategies.

4. We would like to finally mention the wide field of investigations and research opened with genetically modified organisms. This new technology may fundamentally modify the approach to microbial control of pests, taking in consideration the safe use of these new organisms, but not without assessing the risks of different nature attached to genetic engineering and biotechnology.

\section{CONCLUSION}

Toward the beginning of the 21th century, the biocontrol industry is facing difficult challenges:

- the increasing requirement of bioactive agents, adapted to the extension in Europe of sustainable agriculture

- the lack of in house financial ressources for R\&D projects

- some lack of-confidence between the public research institutions and the private industry

- the enforcement of laws and regulations, at the national and at the European levels, simple extrapolation of those prevailing for chemical pesticides, without taking enough in consideration the genuine nature of the microbial control agents

The industry is ready to respond to this challenge and suggest 6 fields of investigations:

1. to increase the cooperation between public research and the industry

2. to relatively allocate more fund for extension, field research

3. to create several "Center of Excellence" for the coordination of research and the supply of generic safety data on given basic organisms (Consensus documents)

4. to concentrate into crops of large economic importance

5. to establish an European wide monitoring and stewardship scheme in order to study the behaviour of released organisms, establish mathematical epidemiological models, prediction tools etc.

6. to consider genetic engineering as a possible field of investigations for the development of suitable and safer genetically modified microbial agents. 